\title{
Regional Economic Diversification and Efficiency: Baumol's Likely Lower Confidence Limit Measure of Risk
}

\author{
Deborah J. Harper and Larry V. St.Louis*
}

\begin{abstract}
In this paper we argue that the appropriate concept of regional economic efficiency is Baumol's lower confidence limit criteria. This implies a substantially reduced subset of the usual Markowitz efficient frontier. We examine this proposition in the context of a tractable equilibrium model with a data set for the province of Saskatchewan. We conclude that the Baumol efficiency criteria suggest maintaining substantial levels of activity in the high-risk, but higher-return, resource sectors of the economy. The results suggest that the cost of stability could be high, in terms of per capita income, if this economy were to diversify too far from its resource-based comparative advantage.
\end{abstract}

\section{INTRODUCTION}

The purposes of this paper are to discuss the relationship between regional risk (instability) and regional efficiency, and to consider the implications for diversification policy for a small open resource-based economy when the risk measure used is the Baumol (1963) "Likely Lower Bound" measure rather than the usual portfolio variance measure.

Regional efficiency is defined in terms of the trade-off between regional return (in income or employment) and the regional risk measure. The trade-off is in turn modeled in the context of the industrial diversity of the region. We argue that the relevant efficiency concept is neither the minimum variance locus suggested by Lande (1994) and Malizia and Ke (1993) nor the minimum variance/ maximum return frontier suggested by Markowitz (1959). Instead, we argue that the relevant concept of regional efficiency is a substantially reduced subset of the Markowitz frontier that results from a semi-variance notion of risk. The semivariance concept of risk that we suggest was first introduced by Roy (1952) and further improved by Baumol (1963).

The Markowitz (1959) concept of efficiency and certainly the minimum variance approach of Lande (1994) and Malizia and Ke (1993) contain many portfolios that would be considered inefficient using the criteria that Baumol (1963) suggests. The portion of the Markowitz efficient set that is considered Baumol inefficient implies risk aversion characteristics that are not realistic in either financial or regional contexts.

It is well known that the Markowitz mean-variance trade-off is optimal if either the utility function of the investor is quadratic, or the distribution of returns

*Economist, Agriculture and Agri-Food Canada; and Professor, Department of Economics, University of Saskatchewan. The authors would like to thank two anonymous reviewers and Donald A. Gilchrist and Robert F. Lucas for their helpful comments. We are responsible for all remaining errors. The opinions stated are those of the authors and do not necessarily represent those of their employers. 
is normal. ${ }^{1}$ Samuelson (1970) points out, "In economics, the relevant probability distributions are not nearly Gaussian, and quadratic utility in the large leads to well known absurdities" (p. 537). The quadratic utility function has the undesirable property of implying increasing absolute, and relative, risk aversion. This in turn implies that a risky investment is an inferior good (see Arrow 1963 and Pratt 1964).

We will compare both the Markowitz and Baumol concepts of efficiency using a tractable equilibrium model applied to an input-output data set for the province of Saskatchewan.

\section{THEORETICAL CONSIDERATIONS}

Few would argue with the notion that an increase in per capita regional income (or employment) improves regional welfare, but many have debated the appropriate measurement and welfare aspects of regional instability and the concept of regional diversity.

Conroy $(1974,1975)$ was the first to borrow the Markowitz (1959) portfolio variance $($ var $=\lambda \tau \Sigma \lambda)$ concept of risk from financial economics and use it as an index of regional diversity. The financial portfolio security proportions $\lambda$ were replaced by regional industrial sectoral (employment) proportions, and the financial covariance matrix $\Sigma$ of security returns was replaced by a matrix of covariances among sectoral employment. A large portfolio variance indicated a relatively poor level of diversification, and a small variance indicated a relatively better level of diversification.

This variance measure of diversity was then compared to a widely accepted index of regional economic instability (REI), based on unemployment. A high degree of correlation was found to exist between the variance diversity measure and REI (see, for example, Brewer 1985).

It was later argued that portfolio variance is a more appropriate measure of instability than an index of diversity. This approach is more in keeping with the concept of risk in the financial economic models. In this context, several authors, St.Louis (1980), Brown and Pheasant (1985), and Hunt and Sheesley (1994), for example, adopted the financial model paradigm that emphasized the trade-off of the expected return (in terms of growth in income or employment), against the variance of that return. The variance in this context was used to measure the uncertainty of the return and was therefore associated with the riskiness of the portfolio. ${ }^{2}$ Then, following the financial literature, the discussion focused on the existence of an industrial mix that might be considered efficient in some sense.

The Markowitz (1959) formulation of the problem was expressed as: minimizing the portfolio variance $V=\lambda \tau \Sigma \lambda$, subject to a given return $E^{*}=\lambda^{\tau} \mu$, to the sum of the $\lambda$ equaling unity, and to all of the portfolio proportions $\lambda_{i}$ being between some appropriate lower and upper bounds, $1_{i}$ and $u_{i}$. This produces a hyperbolic-shaped curve in mean-variance space as $E^{*}$ is varied, that is, locus abc

${ }^{1}$ For a discussion see Tobin (1958).

${ }^{2}$ The use of variance as the appropriate measure of risk, however, depends on either the portfolio returns being described by a two-parameter probability distribution, or the utility function of the investor/policy maker being quadratic (see Tobin 1958). 
in Figure 1. The dual of the problem maximizes the mean return $\mathrm{E}$ subject to a given variance $\mathrm{V}^{*}$ with the same constraints on the $\lambda$ weights as the primal. Again, a hyperbolic curve is generated as the $\mathrm{V}^{*}$ is varied. However, it is not entirely the same curve as in the primal case, rather the arc bcd (see Figure 1). Thus, the primal and dual in combination yield the familiar Markowitz "efficient frontier," between vertical and horizontal tangents as denoted by points $\mathrm{b}$ and $\mathrm{c}$ in Figure 1.

FIGURE 1

Optimization Set

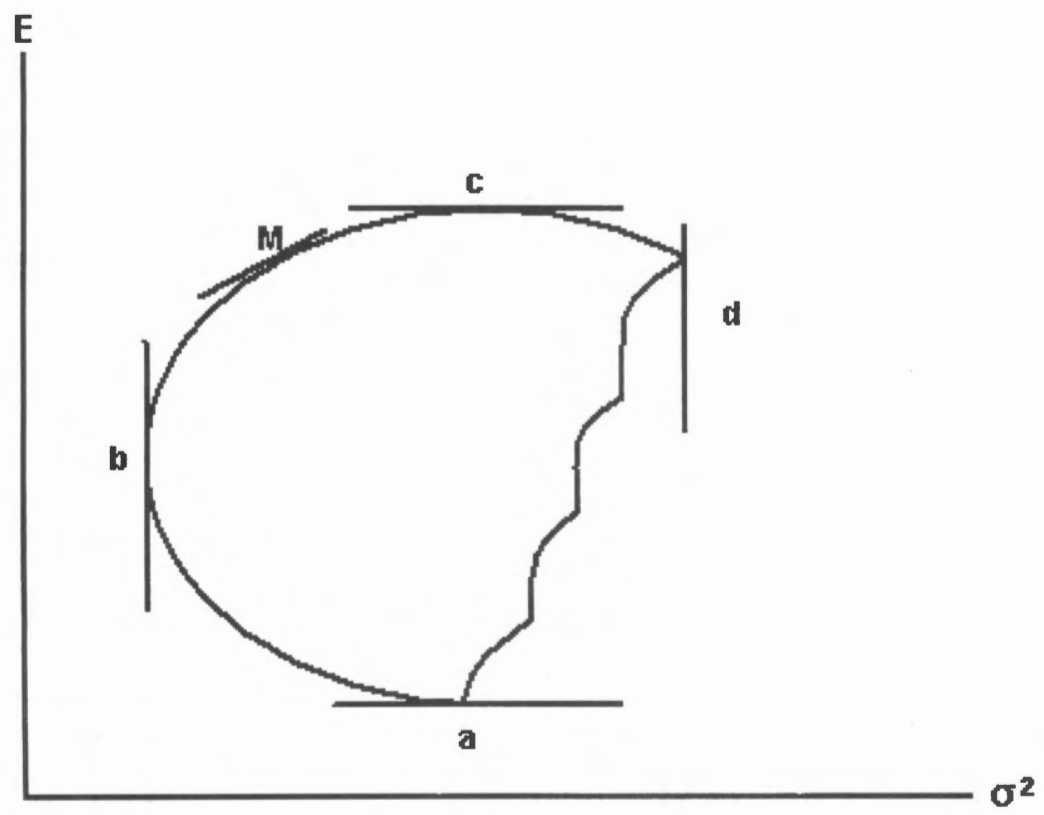

Baumol (1963), following Roy's (1952) notion of safety first, suggested a mean/semi-variance concept of efficiency. This notion further reduces the choice set to a subset of the Markowitz frontier, ${ }^{3}$ from an intermediate point $\mathrm{m}$ to point $\mathrm{c}$ in Figure 1.

The basic idea of semi-variance risk is that the investor does not consider outcomes greater than the expected value to constitute risk that should be avoided. The investor does, however, wish to avoid the risk of bad outcomes below the mean. This notion has roots back to a classic paper by Domar and Musgrave (1944). They suggest, "Since the investor is not only interested in the probability of a negative return, but also in the chances of suffering losses of various magnitudes, the coefficient of risk should be defined more precisely as a function of losses and their probabilities" (p. 493).

The Baumol refinement of the semi-variance risk argument is as follows. Suppose the investor considers the likely lower bound of the portfolio to be $\mathrm{k}$

\footnotetext{
${ }^{3}$ In the stochastic dominance literature (see Bawa 1978, for example) the arc bcd in figure 1 would be referred to as first-order stochastic dominance, which implies more is preferred to less. The Markowitz frontier (arc bc) is referred to as second-order stochastic dominance, which implies that, in addition to more is preferred to less, investors are risk averse. Some upper subset of the Markowitz set is referred to as third-order stochastic dominance. It adds the desirable property of decreasing absolute risk aversion of the investor.
} 
standard deviations below the mean. That is, the investor believes the likely worst case scenario to be:

$$
\mathrm{L}=\mathrm{E}-\mathrm{k} \sigma \text {. }
$$

The investor trades off the expected return $\mathrm{E}$ against the likely lower bound L. If, for portfolios A and B, both are assumed Markowitz efficient and $E_{a}>E_{b}$ and $L_{a}>L_{b}$, then $A$ is superior to $B$. $A$ is superior to $B$ in that it has a higher expected value and the likely worst outcome of $A$ is greater than the likely worst outcome of B. B is not considered efficient (relative to A) in the Baumol sense.

FIGURE 2

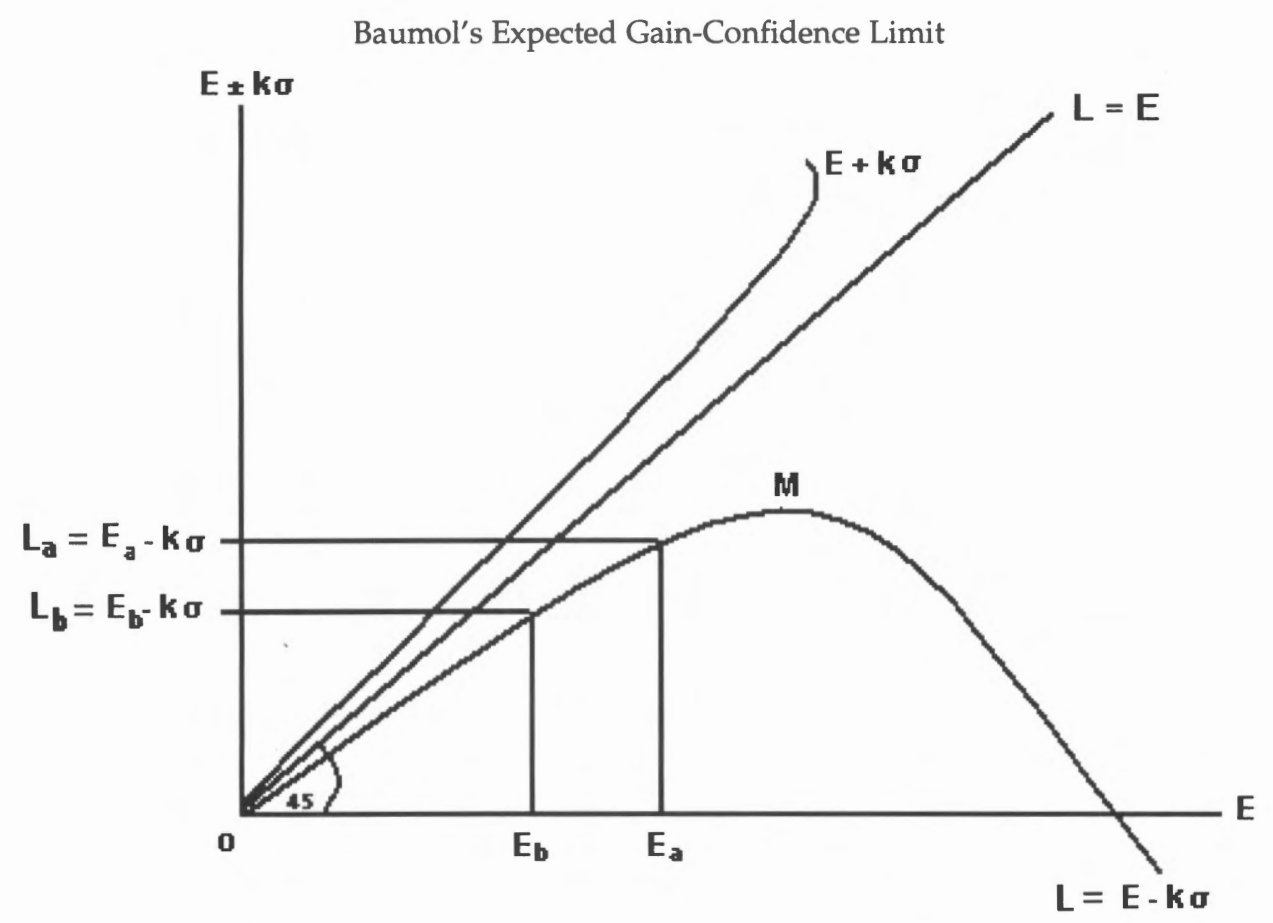

There exists a demarcation portfolio $\mathrm{M}$ between Baumol efficient and Baumol inefficient portfolios somewhere on the Markowitz efficient frontier. For all portfolios $C$ beyond $M$ in Figure 2, $E_{c}>E_{m}$ but $L_{c}<L_{m}$. These portfolios are Baumol efficient in that we cannot say that one is better than the other without more knowledge of the investor's utility function. The M portfolio may be found by maximizing $L$ with respect to $E$ (noting that $\sigma=f(E)$ along the Markowitz frontier). That is:

$$
\frac{\mathrm{dL}}{\mathrm{dE}}=1-\mathrm{k}\left(\frac{\mathrm{d} \sigma}{\mathrm{dE}}\right)=0,
$$

implying $\mathrm{dE} / \mathrm{d} \sigma=\mathrm{k}$. The slope of the efficient frontier $(\mathrm{dE} / \mathrm{d} \sigma)$ at $\mathrm{M}$ is equal to $\mathrm{k}$. Thus, for Baumol efficiency, $\mathrm{dE} / \mathrm{d} \sigma$ must be greater than, or equal to, $\mathrm{k}$.

There remains the question as to the appropriate value of $k$. This obviously depends on the risk aversion of the investor. ${ }^{4}$ The larger the value of $k$ the more ${ }^{4}$ The introduction of $\mathrm{k}$ implies a three-parameter utility function. For a discussion see Fishburn (1977). 
risk averse the investor. For example, if the investor believes that two standard deviations below the mean is the likely lower bound of the portfolio return $\left(R_{\mathrm{P}}\right)$, then Chebyshev's inequality,

$$
\operatorname{Prob}\left\{\left|R_{P}-E\right|>k \sigma\right\} \leq \frac{1}{k^{2}},
$$

implies that there is less than a 12.5 percent chance of doing worse than that lower bound (assuming symmetry). Baumol's investor considers this a remote possibility and therefore not a risk he should be concerned with. ${ }^{5}$ If the investor's choice were $k=3$, he is more risk averse than with $k=2$. Now he considers the lower 5.5 percent tail the remote possibility.

We will compare the Markowitz and Baumol concepts of efficiency with respect to regional industrial diversification in the context of the GilchristSt.Louis (1994) equilibrium model applied to the economy of the province of Saskatchewan. A brief description of this model follows.

\section{MODEL DESCRIPTION}

Gilchrist and St.Louis (1994) develop a simple estimable stochastic equilibrium model of income determination for a small open economy. The model assumes that production decisions have been made, and resources have been committed, before any extraregional commodity price shocks or industry-specific productivity shocks have manifested themselves. All goods are assumed potentially tradeable and are of two varieties, differentiated and nondifferentiated. ${ }^{6}$ The differentiated goods trade at locally determined market-clearing prices $P_{i}$ and the nondifferentiated goods trade at exogenous world prices $\pi_{\mathrm{i}}$. Capital is assumed to be fully mobile regionally and interregionally, with the interest rate parametric to the region. Labor is assumed to be mobile only within sectors of the region.

The realized per capita value added for nondifferentiated $(\mathrm{N})$ commodity $i$ is defined as:

$$
V^{N}=\sum_{i} \pi_{i}\left(\psi_{j} V_{i j}^{t}-U_{i j}\right) \lambda_{j} . \quad i \in N
$$

Here, $\psi_{j}$ is the realization of a productivity shock in industry $\mathrm{j}$. The $\mathrm{V}_{\mathrm{ij}}^{\mathrm{t}}$ and $\mathrm{U}_{\mathrm{ij}}$ are elements of the regional make (transposed) and use matrices scaled by local industry employment, and $\lambda_{j}$ is the industry $j$ employment proportion.

Value added for a differentiated (D) commodity $i$, that trades at locally determined prices $P_{i}$, may be written:

$$
\mathrm{VA}_{\mathrm{i}}^{\mathrm{D}}=\sum_{\mathrm{j}}\left\{\mathrm{P}_{\mathrm{i}}\left[\psi_{\mathrm{j}} \mathrm{V}_{\mathrm{ij}}^{\mathrm{t}}-\left(1-\gamma_{\mathrm{i}}\right) \mathrm{U}_{\mathrm{ij}}\right]-\pi_{\mathrm{i}} \gamma_{\mathrm{i}} \mathrm{U}_{\mathrm{ij}}\right\} \lambda_{\mathrm{i}} . \quad \mathrm{i} \in \mathrm{D}
$$

Here, $\gamma_{i}$ is the import ratio of the ith commodity.

\footnotetext{
${ }^{5}$ The $k=2$ lower bound falls to 5 percent if the probability distribution is normal.

${ }^{b}$ The nondifferentiated goods are typically resource commodities, such as wheat and petroleum.
} 
Local demand for the ith good is assumed Cobb-Douglas $\delta_{i}\left(y / P_{i}\right)$, where $\mathrm{y}$ is per capita income and $\delta_{\mathrm{i}}$ is the budget share. Foreign demand for the ith good is simply assumed as $\phi_{\mathrm{i}}\left(\pi_{\mathrm{i}} / \mathrm{P}_{\mathrm{i}}\right)$, for $\phi_{\mathrm{i}}>0$.

The market-clearing condition for the ith differentiated good is then:

$$
\sum_{\mathrm{j}}\left\{\psi_{\mathrm{i}} \mathrm{V}_{\mathrm{ij}}^{\mathrm{t}}-\left(1-\gamma_{\mathrm{i}}\right) \mathrm{U}_{\mathrm{ij}}\right\} \lambda \mathrm{i}=\delta_{\mathrm{i}}\left(\mathrm{y} / \mathrm{P}_{\mathrm{i}}\right)+\phi_{\mathrm{i}}\left(\pi_{\mathrm{i}} / \mathrm{P}_{\mathrm{i}}\right)
$$

Substituting market clearing into the value added expression for differentiated goods yields a new value added expression, where the local prices $\mathrm{P}_{\mathrm{i}}$ have been eliminated:

$$
\mathrm{VA}_{\mathrm{i}}^{\mathrm{D}}=\delta_{\mathrm{i}} \mathrm{y}+\phi_{\mathrm{i}} \pi_{\mathrm{i}}-\sum_{\mathrm{j}} \pi_{\mathrm{i}} \gamma_{\mathrm{i}} \mathrm{U}_{\mathrm{ij}} \lambda_{\mathrm{i}} .
$$

Total value added per worker is the summation over all commodities of both $\mathrm{N}$ and D types:

$$
\begin{aligned}
\mathrm{VA} & =\sum_{\mathrm{i}}\left(\mathrm{VA}_{\mathrm{i}}^{\mathrm{N}}+\mathrm{VA}_{\mathrm{i}}^{\mathrm{D}}\right) \\
& =\mathrm{y} \sum_{\mathrm{i}} \delta_{\mathrm{i}}+\sum_{\mathrm{i}} \phi_{\mathrm{i}} \pi_{\mathrm{i}}+\sum_{\mathrm{j}} \sum_{\mathrm{i}} \pi_{\mathrm{i}}\left\{\psi_{\mathrm{j}} \mathrm{V}_{\mathrm{ij}}^{\mathrm{t}}-\left(1-\gamma_{\mathrm{i}}\right) \mathrm{U}_{\mathrm{ij}}\right\} \lambda_{\mathrm{j}} .
\end{aligned}
$$

The per worker regional income is then defined as:

$$
y=V A-\sum_{j} \rho_{j} K_{j} \lambda_{j}+r,
$$

where $\rho_{j}$ and Kare the cost of capital and the amount of capital used per unit of labor, respectively (in industry $\mathrm{j}$ ), and $\mathrm{r}$ is the income per worker accruing to residents for capital invested in the region. Thus, $r-\sum_{j} \rho_{j} K_{j} \lambda_{j}$ is the net regionally claimed capital income per worker. Substituting for VA from above yields an expression for realized ex post per worker income:

$$
y=\left(1-\sum_{i} \delta_{i}\right)^{-1}\left\{\sum_{i} \phi_{i} \pi_{i}+\sum_{j}\left[\sum_{i} \pi_{i}\left(\psi_{j} V_{i j}^{t}-\left(1-\gamma_{i}\right) U_{i j}\right)-\rho_{j} K_{j}\right] \lambda_{j}+r\right\} .
$$

This expression is stochastic ex ante. The underlying assumptions are that the foreign prices $(\pi)$ and technology shocks $(\psi)$ are jointly independent random variables with unit means and with finite variance-covariance matrices $\Sigma_{\pi}$ and $\Sigma_{\psi}$.

Computing the mean and variance of the above expression yields the following expressions:

$$
\begin{aligned}
& E(y)=(1-\delta)^{-1}\left(\mathrm{r}^{\mathrm{t}} \mathrm{C} \lambda+\mathrm{t}^{\mathrm{t}} \phi+\mathrm{r}-(\rho \circ \mathrm{k})^{\mathrm{t}} \lambda\right) \text { and } \\
& \sigma^{2}(\mathrm{y})=(1-\delta)^{-2}\left\{\lambda^{\mathrm{t}}\left[\Sigma_{\psi} \circ \mathrm{B}^{\mathrm{t}}\left(\Sigma_{\pi}+\mathrm{u}^{\mathrm{t}}\right) \mathrm{B}+\mathrm{C}^{\mathrm{t}} \Sigma_{\pi} \mathrm{C}\right] \lambda+2 \phi^{\mathrm{t}} \Sigma_{\pi} \mathrm{C} \lambda+\phi^{\mathrm{t}} \Sigma_{\pi} \phi\right\},
\end{aligned}
$$

where:

$B$ is an $L \times J$ (commodity $x$ industry) matrix with elements $V_{i j}^{t}$ if $i$ is a nondifferentiated commodity and 0 if $i$ is a differentiated commodity;

$\mathrm{C}$ is an $\mathrm{L} \times \mathrm{J}$ matrix with elements $\left(\mathrm{V}_{\mathrm{ij}}^{\mathrm{t}}-\mathrm{U}_{\mathrm{ij}}\right)$ if $\mathrm{i}$ is a nondifferentiated commodity and $\left(-\gamma_{i} U_{i j}\right)$ if $i$ is a differentiated commodity; 
$\phi$ is an $L \times 1$ vector with elements $\phi_{i}$;

$\imath$ is an $\mathrm{L} \times 1$ unit vector;

$\delta=\Sigma_{\mathrm{i}} \delta_{\mathrm{i}} ;$ and

${ }^{\circ}$ denotes a Hadamard product.

Impacts on the per worker income of the region, in terms of changes in the mean and variance of income $\left(\Delta \mathrm{E}\right.$ and $\left.\Delta \sigma^{2}\right)$ may then be examined in the context of changes to the activity vector $(\Delta \lambda)$. We apply this model to a data set for the province of Saskatchewan in the context of the Markowitz and Baumol concepts of efficiency.

\section{THE REGION}

Saskatchewan's economy is the most variable of all the Canadian provinces. Saskatchewan's standard deviation in growth rate of GDP has been approximately three times larger than the Canadian average over the last four decades. This variability is most certainly related to the industrial mix. Approximately 27 percent of the labor force is still involved in agriculture, ${ }^{7} 4$ percent in other resource extraction, 7 percent in construction, 7 percent in manufacturing, and 55 percent in the services.

The provincial governments of Saskatchewan have a long history of promoting industrial diversification policies in attempts to increase regional income and employment, and to improve stability. The direction that the diversification should take, however, has been the topic of much debate. ${ }^{8}$ Policy initiatives over the years have included providing locational incentives to a steel rolling mill, a pulp and paper plant, a heavy oil refinery, a meat packing plant, an ethanol plant, a large insurance company, and various high-technology enterprises. Some policy initiatives have been successful ${ }^{9}$ and some have not, but most have been aimed at the manufacturing sector. The manufacturing sector, however, is small and does not have a high degree of local linkages. The historical locational disadvantages, such as distance from markets, lack of a skilled labor force, and little in the way of locally available (nonresource) intermediate inputs, has hindered the development of this sector.

\section{THE DATA}

Estimates of the ex ante outputs $\left(\psi_{\mathrm{j}} \mathrm{V}_{\mathrm{ij}} \lambda_{\mathrm{j}}\right)$, and the ex ante inputs $\left(\mathrm{U}_{\mathrm{ij}} \lambda_{\mathrm{g}}\right)$, were obtained from the 1984 Statistics Canada Input-Output tables for the province of Saskatchewan. The implicit assumption being that $\psi_{j}, \pi_{i}$, and $\rho$ all equaled unity initially. These tables were aggregated into nine industries and

\footnotetext{
${ }^{7}$ The census of 1951 indicated that 49 percent of the labor force was directly engaged in agriculture, but the 1961 census indicated the proportion had fallen to 37 percent.

${ }^{8}$ Some of the suggestions have been to add value to what we produce, to attract high-technology footloose industries, to diversify the agriculture product mix, and even to diversify the location of manufacturing activity from urban to rural.

95ee Stabler and St.Louis (1988) for a postproject evaluation of the steel mill diversification initiative.
} 
twenty-seven commodities. ${ }^{10}$ The decision to apply the analysis to basically onedigit SIC categories was made to avoid the issue of picking winners from sectors that comprise small fractions of the labor force and thereby focus on the issue of diversification among the major sectors. ${ }^{11}$ The nine industries and their respective employment shares are listed in Table 1 while the twenty-seven commodities are listed in appendix Table A1.

\section{TABLE 1}

Saskatchewan Allocation of Labor by Industry, 1984

\begin{tabular}{lc}
\hline & Employment Share \\
\hline Agriculture (AG) & 0.26850 \\
Forestry Fish.\& Trapping (FFT) & 0.00359 \\
Mining \& Oil Extraction (MOE) & 0.03091 \\
Light Manufacturing (LMAN) & 0.04081 \\
Heavy Manufacturing (HMAN) & 0.03215 \\
Construction (CONST) & 0.06756 \\
Trans.Stor.Comm.Elect. Pow.Gas \& Other Util.(TCU) & 0.09279 \\
Trade - Wholesale \& Retail (TRADE) & 0.23003 \\
Fin.Insur.Real Estate \& Bus.\& Per.Serv.(FIRES) & 0.23363 \\
\hline
\end{tabular}

The $27 \times 27$ foreign price covariance matrix $\left(\Sigma_{\pi}\right)$ was computed from the residuals from first-order autoregressions applied to a time series of Canadian commodity price indices from 1961 to 1996 . A similarly ordered technology shock matrix $\left(\Sigma_{\psi}\right)$ was computed, but with the shock applying only to the commodity grain. This matrix was then diagonal with a single entry in the grains row and column. It was estimated as the sample variance of Saskatchewan spring wheat yields from 1951 to 1988 .

Capital stock data by industry is not available for Saskatchewan, so shares of the national net capital stocks were allocated to each industry according to that industry's proportional share of gross national output. The allocations were then scaled by industry employment to derive the per worker capital vector $\mathrm{K}$. The cost of capital for each industry $(\rho)$ was calculated as the real yield on long-term corporate bonds plus the capital cost allowance per dollar of net capital stock allowed for each industry. The $r$, representing the income from capital accruing to regional residents, was calculated as a residual by the calibration of per worker income to the observed 1984 value.

The import coefficients $\left(\gamma_{\mathrm{i}}\right)$ were calculated as the ratios of imports to total local uses (intermediate and final) for each commodity. The foreign demand coefficients for domestically produced differentiated commodities $\left(\phi_{\mathrm{i}}\right)$ were computed as the fraction that an export formed of total exports, and the domestic demand coefficients $\left(\delta_{\mathrm{i}}\right)$, for domestically produced differentiated commodities, were computed as fractions of total final domestic demand.

\footnotetext{
${ }^{10}$ The aggregation of an input-output table almost always introduces a certain amount of bias into impact analysis, and we suspect our model is not immune, even though we don't compute an inverse. See Miller and Blair (1985) for a discussion.

${ }^{11}$ Diversifying away from agriculture into manufacturing is one level of problem while the choice of which industries within manufacturing is a second-order problem.
} 


\section{MODEL ESTIMATION}

The Sharpe (1970) programming algorithm was used to generate the Markowitz efficient frontier. It may be thought of as maximizing a hypothetical utility function with linear indifference curves, $E=a+b \sigma$, subject to the equality and inequality constraints imposed by the Markowitz problem and successive values of the marginal rate of substitution (b). ${ }^{12}$

$$
\begin{aligned}
& \text { Max } a=E-b \sigma \\
& \text { s.t. } \Sigma_{i} \lambda_{i}=1, \\
& l_{i} \leq \lambda_{i} \leq u_{i} \text { for all } i .
\end{aligned}
$$

For convenience, we restate the problem as a minimization with respect to the $\sigma$ intercept as follows, with $\mathrm{E}$ and $\sigma$ defined as above:

The estimated frontier is very sensitive to the choice of the lower and upper limits, $1_{i}$ and $u_{i}$, as it is with any financial portfolio. Thus, to be realistic, these limits must be chosen with care. It was thought that an examination of the concentration ratios, computed from the 1991 census of employment, for the three prairie provinces would be instructive in this regard.

TABLE 2

Location Quotients for the Three Prairie Provinces, 1991

\begin{tabular}{lccc}
\hline & Alberta & Saskatchewan & Manitoba \\
\hline Agriculture & 1.67 & 4.72 & 1.98 \\
Forestry & 0.37 & 0.31 & 0.43 \\
Mining \& Oil & 3.74 & 1.57 & 0.72 \\
Light Manu. & 0.51 & 0.31 & 0.89 \\
Heavy Manu. & 0.44 & 0.34 & 0.52 \\
Construction & 1.22 & 1.07 & 0.89 \\
Trans.Com.\& Util. & 1.03 & 0.99 & 1.21 \\
Trade & 0.98 & 1.01 & 0.95 \\
Fire.Serv.\& Pub.Ad. & 1.05 & 1.02 & 1.07 \\
\hline
\end{tabular}

The concentration ratios for the service industries tend to be not greatly different from unity across all three provinces, suggesting that there is not great scope for changing the activity levels in these industries. ${ }^{13}$ The ratios for the basic industries, however, vary considerably from unity, and from each other. There would appear to be a potential to enhance activity levels of the export industries and reduce import dependence by increasing activity in those industries.

\footnotetext{
${ }^{12}$ As the $b$ value is varied from zero through infinity, the Markowitz frontier is revealed, and when $b=k$ the boundary of the Baumol efficient set is found.

${ }^{13}$ There are of course exceptions. Specialized service industries, like agricultural or mining services, for example, are not population based and could have expansion potential. Indeed, one provincial diversification initiative in the early 1990s was to provide sufficient incentives to induce a major insurance company to relocate from central Canada.
} 
TABLE 3

Alberta and Saskatchewan 1986 Labor Allocations

\begin{tabular}{lcc}
\hline & Alberta & Saskatchewan \\
\hline AG & 0.10955 & 0.24593 \\
FFT & 0.00433 & 0.00516 \\
MOE & 0.08249 & 0.03344 \\
LMAN & 0.04645 & 0.03755 \\
HMAN & 0.05520 & 0.03619 \\
CONST & 0.09333 & 0.07827 \\
TCU & 0.10696 & 0.09759 \\
TRADE & 0.21812 & 0.21875 \\
FIRES & 0.28459 & 0.24719 \\
\hline
\end{tabular}

Following the suggestion of Schoening and Sweeney (1992), that adjacent jurisdictions with similar resource bases be used as benchmarks for diversification policies, we chose Alberta as a target. Saskatchewan has long been envious of the performance of the Alberta economy, and Alberta has a somewhat similar resource base. We then let the activity levels range between the observed Alberta and Saskatchewan proportions for 1986 (see Table 3). It should be observed from Table 3 that the labor proportions in the service industries for both provinces were very similar, consistent with their location quotients being very close to unity.

The employment shares for each sector were compared between the two provinces and the lowest percentage share was deemed to be the minimum employment requirement, and was used as $l_{i}$. The larger proportion was used for $u_{\mathrm{i}}$. The Sharpe (1970) algorithm was then used to produce several portfolios in this context along a Markowitz efficient frontier (see Table 4). ${ }^{14}$

TABLE 4

Sharpe-Markowitz Efficient Portfolios

\begin{tabular}{|c|c|c|c|c|c|c|c|c|c|c|}
\hline Portfolio & 1 & $2^{*}$ & 3 & $4^{\#}$ & 5 & 6 & 7 & 8 & 9 & 10 \\
\hline $\mathrm{E}(\$ 000)$ & 37.6 & 37.4 & 37.2 & 36.1 & 36.0 & 35.1 & 32.6 & 32.2 & 31.7 & 19.8 \\
\hline$\sigma(\$ 000)$ & 5.5 & 4.6 & 4.5 & 4.2 & 4.2 & 4.1 & 3.8 & 3.7 & 3.6 & 2.8 \\
\hline
\end{tabular}

\begin{tabular}{lllllllllll}
\hline AG & 0.197 & 0.159 & 0.150 & 0.135 & 0.134 & 0.109 & 0.109 & 0.109 & 0.109 & 0.134 \\
FFT & 0.005 & 0.005 & 0.005 & 0.005 & 0.005 & 0.005 & 0.005 & 0.005 & 0.005 & 0.005 \\
MOE & 0.083 & 0.083 & 0.083 & 0.083 & 0.083 & 0.083 & 0.083 & 0.083 & 0.081 & 0.043 \\
LMAN & 0.038 & 0.038 & 0.038 & 0.038 & 0.039 & 0.047 & 0.047 & 0.047 & 0.047 & 0.047 \\
HMAN & 0.036 & 0.036 & 0.036 & 0.036 & 0.036 & 0.036 & 0.052 & 0.054 & 0.055 & 0.055 \\
CONST & 0.078 & 0.078 & 0.078 & 0.093 & 0.093 & 0.093 & 0.093 & 0.093 & 0.093 & 0.093 \\
TCU & 0.098 & 0.098 & 0.107 & 0.107 & 0.107 & 0.107 & 0.107 & 0.107 & 0.107 & 0.107 \\
TRADE & 0.219 & 0.219 & 0.219 & 0.219 & 0.219 & 0.219 & 0.219 & 0.219 & 0.219 & 0.219 \\
FIRES & 0.247 & 0.285 & 0.285 & 0.285 & 0.285 & 0.285 & 0.285 & 0.285 & 0.285 & 0.285 \\
\hline
\end{tabular}

The * and \# indicate the portfolios associated with the Baumol maximum point $\mathrm{M}$ for $\mathrm{k}=2$ and $\mathrm{k}=3$, respectively.

A few observations can be made with respect to the nature of this frontier. First, the Agriculture sector is increasingly, and severely, reduced from the highest return portfolio to the lowest return portfolio. ${ }^{15}$ Second, the extractive industries,

\footnotetext{
${ }^{14}$ It should be noted that the frontier is a continuum. The computer algorithm, however, produces only a few corner portfolios on it.

${ }^{15}$ If we had dissaggregated the data set and diversified within the agriculture sector (say, among grains, oil seeds, and livestock), this conclusion might well have been altered somewhat, but not enough to change the general conclusion since grains far outweigh the other subsectors.
} 
Forestry and Mining, are high risk but even higher return, and are included in virtually all efficient portfolios, except those at the very low end. Third, the two manufacturing industries and Construction all exhibit similar behavior. These industries, tending to exhibit lower-risk-moderate-return patterns, are all at their lower limits in the high-return-high-risk portfolios, but increase to their maximum limits at the low-return-low-risk end. Finally, the lowest-risk service industries are in virtually all portfolios at their maximum values, except for those

FIGURE 3

Baumol Likely Lower Bound $\mathrm{L}=\mathrm{E}-\kappa \sigma$

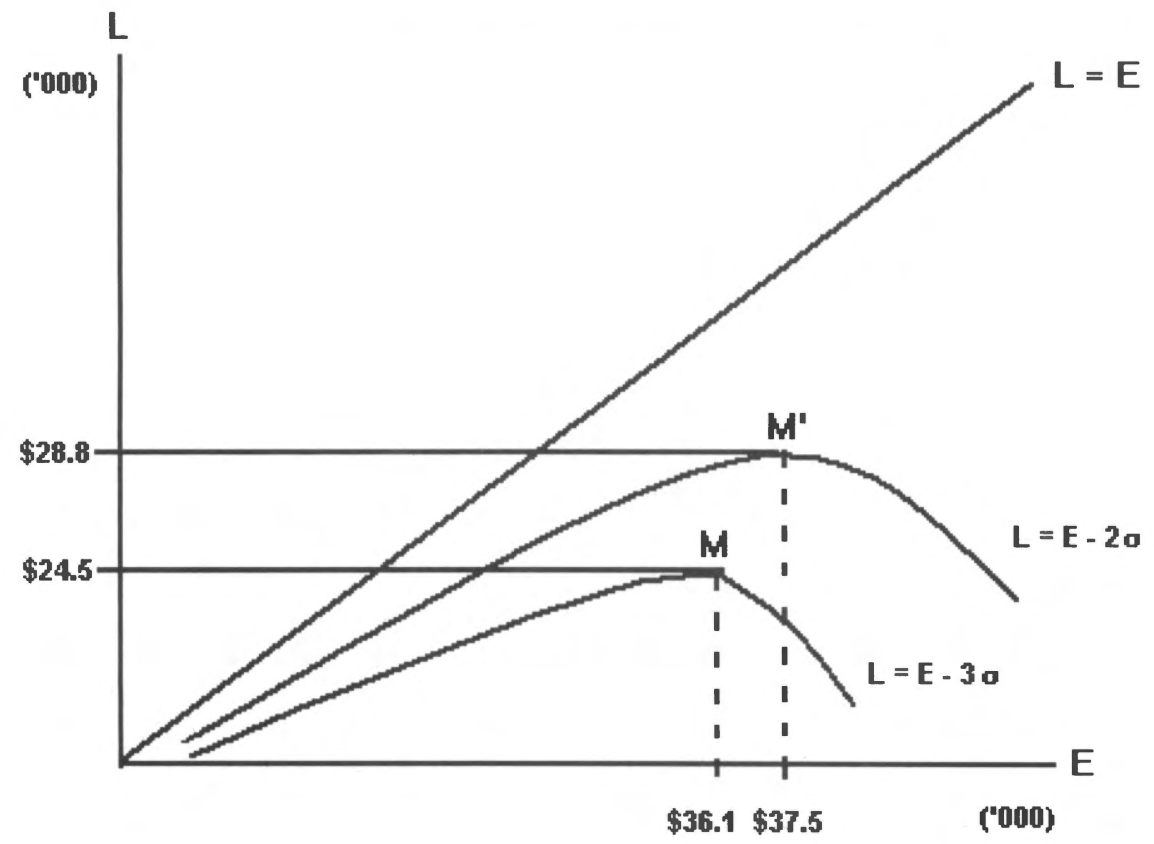

FIGURE 4

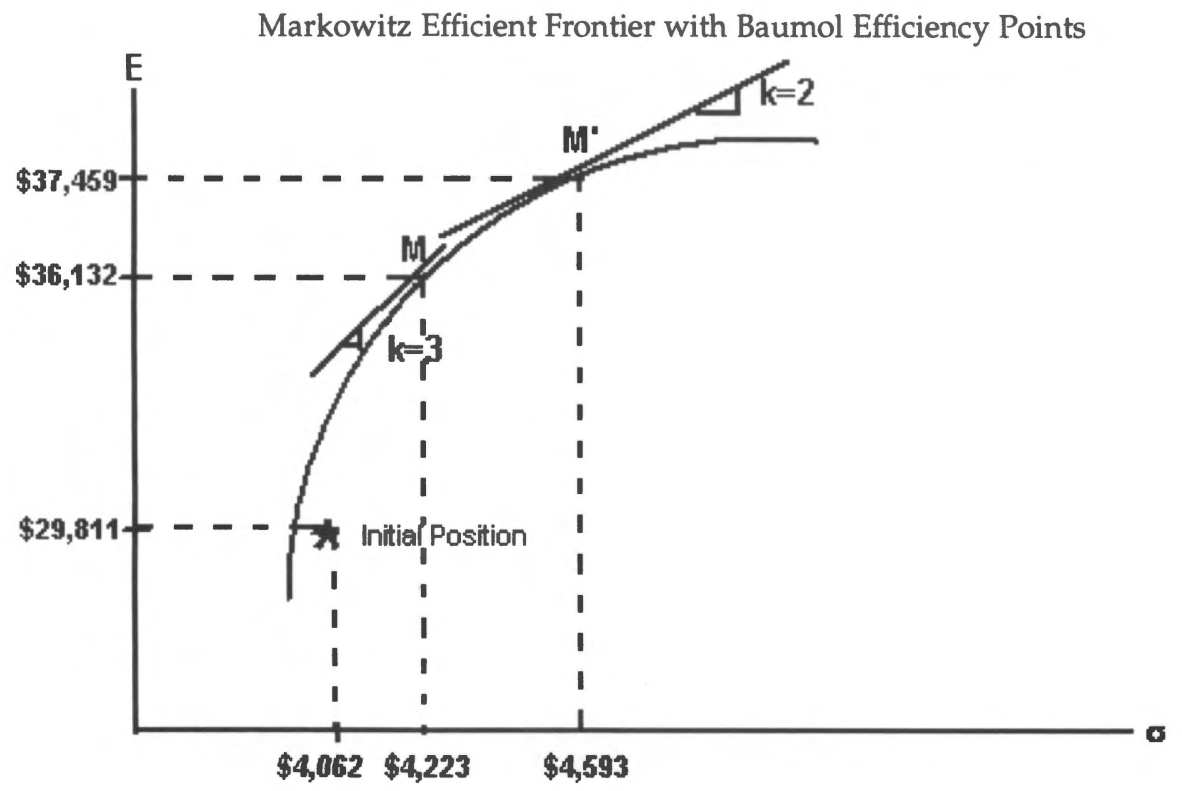


portfolios with the highest returns. It might also be observed that the final corner portfolio, ${ }^{16}$ the one generating the lowest per worker income, has reintroduced agriculture and diversified away from the high-income-high-risk Mining and Oil Extraction industry.

The Baumol maximum point for $\mathrm{k}=2$ was found to be the second Markowitz portfolio. This implies that only the first and second highest income portfolios are Baumol efficient, and the remaining portfolios, 3 through 10, are not. (See Table 5.) For a higher level of risk aversion, $k=3$, only the first four portfolios are Baumol efficient. The remainder are not. (See Figures 3 and 4.)

TABLE 5

Baumol Expected Gain-Confidence Limits

\begin{tabular}{ccccc}
\hline & $\begin{array}{c}\text { Expected } \\
\text { Value }\end{array}$ & $\begin{array}{c}\text { Standard } \\
\text { Deviation }\end{array}$ & \multicolumn{2}{c}{$\begin{array}{c}\text { Likely Lower Limits } \\
\mathrm{L}=\mathrm{E}-\mathrm{k} \sigma\end{array}$} \\
\hline Portfolio & $\mathrm{E}$ & $\sigma$ & $\mathrm{L}(\mathrm{k}=2)$ & $\mathrm{L}(\mathrm{k}=3)$ \\
\hline 1 & 37,577 & 5,478 & 26,621 & 21,143 \\
2 & 37,459 & 4,593 & $28,773^{*}$ & 25,680 \\
3 & 37,224 & 4,450 & 28,324 & 23,874 \\
4 & 36,132 & 4,223 & 27,686 & $24,255 \#$ \\
5 & 36,016 & 4,207 & 27,602 & 23,395 \\
6 & 35,169 & 4,087 & 26,995 & 22,908 \\
7 & 32,588 & 3,750 & 25,088 & 21,338 \\
8 & 32,239 & 3,715 & 24,809 & 21,094 \\
9 & 31,699 & 3,661 & 24,277 & 20,716 \\
10 & 19,753 & 2,816 & 14,121 & 11,305 \\
\hline
\end{tabular}

The * and \# indicate the Baumol efficiency points for $k=2$ and $k=3$, respectively.

A few observations may be made in this regard. For $k=2$ and $k=3$, the Baumol sets of efficient portfolios both contain reduced amounts of agricultural activity, but also considerably more than the minimum requirements. The two Baumol efficient sets include the other primary extractive industries at their maximum levels, but hold the Manufacturing sector to its minimum level. Trade and Transportation, Communication, and other Utilities did not have sufficient scope to vary, but Construction and Finance tend to be at their upper limits.

Some of these results are as expected, but others are somewhat counter to the conventional wisdom. The diversification away from Agriculture is as expected. Agriculture is a high-risk industry, but does not have the expected per worker income to match. The extractive industries are high risk, but tend also to have very high expected incomes. Baumol efficiency, however, does not suggest expanding the manufacturing industries at the expense of the primary extractive sector. Diversification away from the primary industries and into manufacturing has often been suggested as the appropriate policy objective of primary product producing regions. The Baumol criteria suggests that policy makers should be cautious with respect to this strategy. The gain in provincial stability could be fairly costly in terms of considerably lower per capita incomes.

${ }^{16}$ Portfolios with lower incomes than portfolio 10 reported in Table 4 were associated with increasing risk levels, and were therefore not Baumol, nor Markowitz, efficient and were not reported. 


\section{CONCLUSIONS}

We have argued that the minimum variance and Markowitz meanvariance efficiency criteria imply an unwarranted degree of risk aversion that could imply inappropriate targets for regional development policy. We have suggested as an alternative the theoretically more appealing Baumol lower likelihood limit efficiency criteria, a notion of efficiency that implies a subset of the Markowitz efficient set, which is in turn a subset of the minimum variance locus. We have estimated a Markowitz frontier and we have identified the Baumol efficient subsets using a 1984 data set for the province of Saskatchewan in the context of a tractable equilibrium model.

We conclude that the higher-risk resource-based industries, because of their higher per worker incomes and linkages within the economy, should not be ignored as targets of diversification initiatives. That is, it could be costly for such a region to aim its diversification policy in a direction that is away from its resource base and ignore its comparative advantage. This is contrary to the new conventional wisdom that suggests that the direction of diversification for a resource-based economy should be away from the resource base and towards a manufacturing/service base. Perhaps this focus is too narrow and from an overly risk-averse perspective. We are not suggesting that an initiative that reduces regional risk, leaving regional income unaltered, is not a welfare improvement. It is, but low per capita incomes are not much of an inducement for growth in economic activity. The lessons of Ricardo should not be completely forgotten. 


\section{APPENDIX}

TABLE A1

1984 Input-Output Commodities

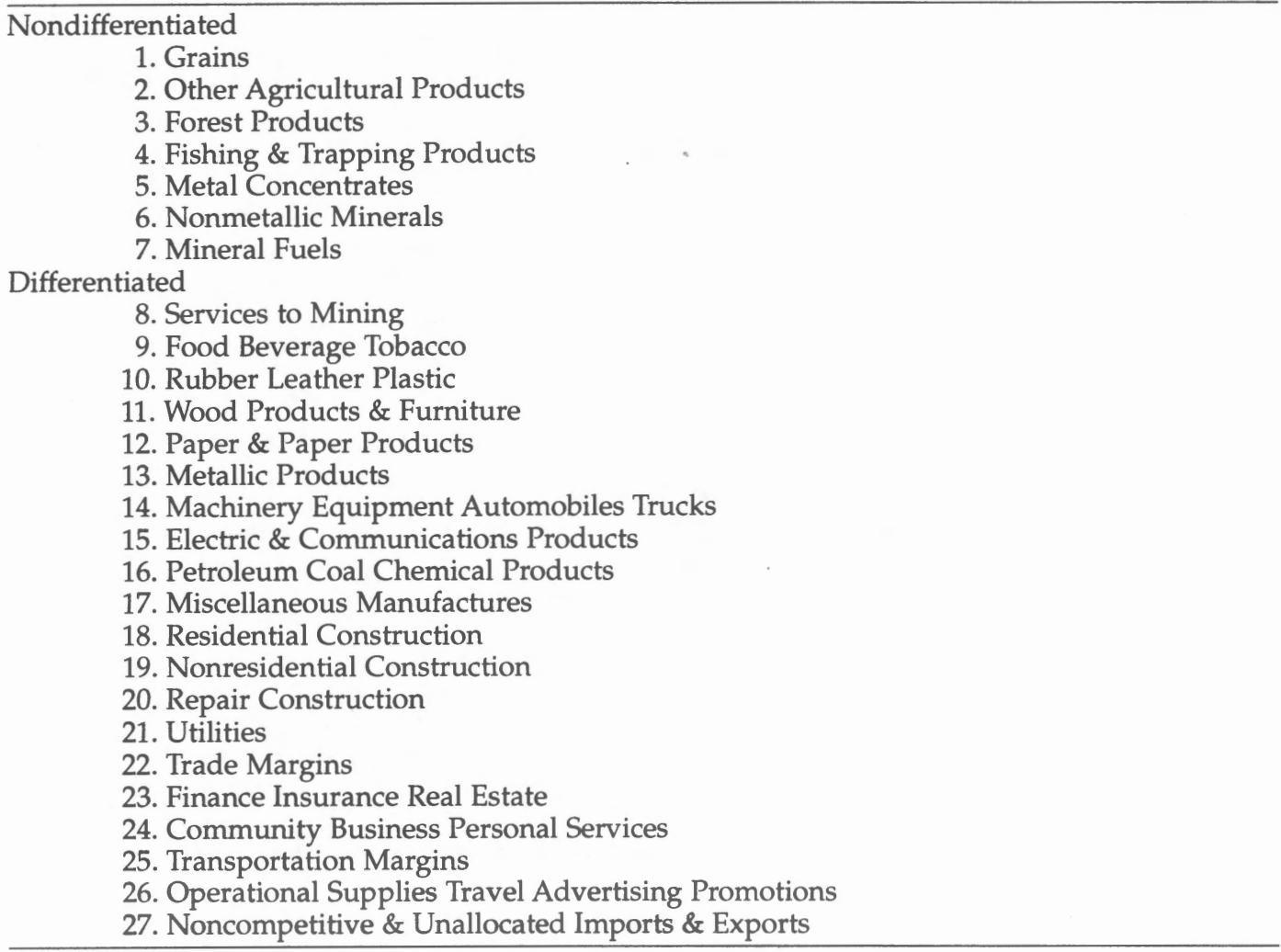

\section{REFERENCES}

Arrow, Kenneth J. "Comment on Duesenberry's Portfolio Approach to the Demand for Money and Other Assets." Review of Economics and Statistics 45 (1963), 24-27.

Baumol, William J. "An Expected Gain-Confidence Limit Criterion for Portfolio Selection." Management Science 10 (1963), 174-182.

Bawa, Vijay. "Safety-First, Stochastic Dominance, and Optimal Portfolio Choice." Journal of Financial and Quantitative Analysis 13 (1978), 417-432.

Brewer, H.L. "Measures of Diversification: Predictors of Regional Economic Instability." Journal of Regional Science 25 (1985), 463-469.

Brown, D.J., and J. Pheasant. "A Sharpe Portfolio Approach to Regional Economic Analysis." Journal of Regional Science 25 (1985), 51-63.

Conroy, Michael E. "Alternative Strategies for Regional Industrial Diversification." Journal of Regional Science 14 (1974), 31-46.

. "The Concept and Measurement of Regional Industrial Diversification." Southern Economic Journal 41 (1975), 492-505. 
Domar, Evsey D., and Richard A. Musgrave. "Proportional Income Taxation and Risk-Taking." Quarterly Journal of Economics 58 (1944). Reprinted in Richard A. Musgrave and Carl Shoupe (eds.) Readings in the Economics of Taxation (Homewood, IL: Richard D Irwin, Inc., 1959), 493-524.

Fishburn, P.C. "Mean-Risk Analysis with Risk Associated with Below-Target Returns." American Economic Review 67 (1977), 116-126.

Gilchrist, D.A., and L.V. St.Louis. "Directions for Diversification with an Application to Saskatchewan." Journal of Regional Science 31 (1991), 273-289.

. "An Equilibrium Analysis of Regional Industrial Diversification." Regional Science and Urban Economics 24 (1994), 115-133.

Hunt, G.L., and T.J. Sheesley. "Specification and Econometric Improvements in Regional Diversification Analysis." Journal of Regional Science 34 (1994), 217-235.

Lande, Paul S. "Regional Industrial Structure and Economic Growth and Instability." Journal of Regional Science 34 (1994), 343-360.

Malizia, Emil E., and Shanzi Ke. "The Influence of Economic Diversity on Unemployment and Stability." Journal of Regional Science 33 (1993), 221-235.

Markowitz, Harry M. Portfolio Selection: Efficient Diversification of Investments. New Haven, CT: Yale University Press, 1959.

Miller, Ronald E., and Peter D. Blair. Input-Output Analysis: Foundations and Extensions. Englewood Cliffs, NJ: Prentice Hall, 1985.

Pratt, J.W. "Risk Aversion in the Small and the Large." Econometrica 32 (1964), 122-136.

Roy, A.D. "Safety First and the Holding of Assets." Econometrica 20 (1952), 431-449. Samuelson, Paul A. "The Fundamental Approximation Theorem of Portfolio Analysis in Terms of Means, Variances and Higher Moments." The Review of Economic Studies 37 (1970), 537-542.

Schoening, Niles C., and Larry E. Sweeney. "Proactive Industrial Development Strategies and Portfolio Analysis." The Review of Regional Studies 22 (1992), 227-238.

Sharpe, W.F. Portfolio Theory and Capital Markets. New York: McGraw-Hill, 1970. Stabler, Jack C., and Larry V. St.Louis. "Saskatchewan Steel: A Regional Industrial Impact Analysis." Canadian Journal of Regional Science 11 (1988), 133-145.

St.Louis, L.V. "A Measure of Regional Efficiency and Diversification." Annals of Regional Science 14 (1980), 21-30.

Tobin, James. "Liquidity Preference as Behavior Towards Risk." Review of Economic Studies 25 (1958), 65-86. 
